\title{
Experimental Study of Steam and Carbon Dioxide Microwave Plasma for Advanced Thermal Treatment Application
}

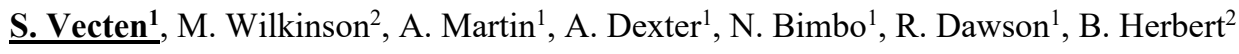 \\ ${ }^{1}$ Engineering Department, Lancaster University, LA1 4YW, United-Kingdom \\ ${ }^{2}$ Stopford Projects Ltd, Lancaster University, The Gordon Manley Building, LA1 4YQ, United-Kingdom \\ First Author: Simon Vecten \\ Corresponding Author: Ben Herbert \\ Corresponding Author email: ben.herbert@stopford.co.uk
}

List of Authors and email address:

- SimonVecten, s.vecten@lancaster.ac.uk

- MichaelWilkinson, michael.wilkinson@stopford.co.uk

- Alastair Martin,a.martin1@lancaster.ac.uk

- Amos Dexter,a.dexter@lancaster.ac.uk

- NunoBimbo,n.bimbo@lancaster.ac.uk

- RichardDawson,r.dawson@lancaster.ac.uk

- Ben Herbert, ben.herbert@stopford.co.uk

\begin{abstract}
Pollution reduction from waste management and energy generation is necessary to mitigate climate change and is one of the major challenges of the $21^{\text {th }}$ century. This can be achieved through the development of innovative energy recovery technologies from biomass and wastes, such as microwave plasma gasification. An envelope of stable $\mathrm{CO}_{2}$ plasma operation is described, by varying working gas flow rate at applied microwave powers between 1 and $6 \mathrm{~kW}$, whereas $\mathrm{H}_{2} \mathrm{O}$ plasma operation is possible with flow rate ranging from 20 to $50 \mathrm{~g} / \mathrm{min}$ and microwave powers between 2.5 and $6 \mathrm{~kW}$. The temperature generated in a large chamber connected to the plasma torch is recorded, reaching up to $850^{\circ} \mathrm{C}$, showing a heterogeneous temperature distribution. In addition, optical emission spectroscopy measurements provide an insight into plasma chemistry and demonstrate the dissociation of $\mathrm{CO}_{2}$ and $\mathrm{H}_{2} \mathrm{O}$ molecules at extremely high temperatures of up to $6,300^{\circ} \mathrm{C}$ assuming local thermodynamic equilibrium. The experimental results demonstrate that the microwave plasma torch provides an ideal environment for gasification with high temperature and very chemically reactive species. This study provides valuable information for the design of microwave plasma gasification reactors with great potential for effective solid feedstock conversion into high quality syngas for energy production.
\end{abstract}

Keywords: Microwaves, Plasma, Carbon dioxide, Steam, Gasification
Abbreviation:
ATT: Advanced Thermal Treatment
DC: Direct Current
MPT: Microwave Plasma Torch
OES: Optical Emission Spectroscopy
SLPM: Standard Litre per Minute
SOFC: Solid Oxide Fuel Cell 


\section{Introduction}

Industrialisation of society has enabled an enhanced standard of living, facilitated by easier access to electricity and goods. The consequence of this, however, is the emission of greenhouse gases, from fossil fuel combustion, which in turn contribute towards climate change [1]. In parallel the industrialisation of society is also driving the ever-increasing generation of waste which itself causes unintended health, safety and environmental issues, all of which are exacerbated in emerging economies [2]. As such, the provision of affordable, reliable and low-carbon energy and the development of sustainable waste management practices remain to be two of the largest challenges to mankind.

Today it is estimated that circa $70 \%$ of the solid waste generated globally is either sent to landfill or dumped [2], of which both practices are recognised as being the least sustainable option according to the Waste Hierarchy presented in European Directive 2008/98/EC [3]. In contrast, the directive stipulates that the optimum solutions for waste management are to reduce and reuse wastes at source, with recycling and energy recovery being the next best options should avoidance of waste generation not be possible [3]. As such, Governments across Europe have set ambitious targets, with respect to waste management, with an ultimate aim for less than $10 \%$ of all wastes generated to be disposed of to landfill by 2030 [4]. Energy recovery is recognised as the best treatment option for nonrecyclable waste that would otherwise be disposed of to landfill. Waste can be used as a fuel for low-carbon energy generation and in doing so offset demand for fossil fuel derived energy. Incinerators are currently the predominant waste-to-energy technology deployed globally for waste destruction and subsequent energy recovery, whereby facilities are often large centralised units (increasing waste miles), that operate at low efficiencies, whilst also requiring significant exhaust gas treatment in order to comply with strict emissions regulations [5]. However, given the increasing transition of energy and waste management companies towards the development of distributed energy generation and waste management assets, an alternative opportunity exists whereby lowcarbon energy can be generated from waste at source. Advanced thermal treatment (ATT), comprising gasification and pyrolysis process plant are one such emerging group of technologies that may present a significant opportunity for decentralised energy generation and waste management and in doing so reducing the polluting and costly requirement to transport waste to centralised facilities. Gasification can be defined as the thermal decomposition of a solid feedstock in an oxidizing environment, leading to the generation of a synthetic gas (syngas) composed of mainly $\mathrm{CO}$ and $\mathrm{H}_{2}$. The resultant syngas from gasification process can be used for electricity or heat generation, using either a gas engine, gas turbine or fuel cell. One of the many virtues of gasification is its environmental performance [5]. This is especially true for thermal plasma gasification which can achieve almost complete waste conversion as well as the production of a clean syngas due to the exceptional properties of plasma $[6,7]$.

According to Fridman, plasma can be defined as the fourth state of the matter after solids, liquids and gases [8]. Plasma is formed through the phenomenon of ionization, which is the dissociation of electrons from atoms or molecules, leading to the formation of positively charged ions. The presence of ions, electrons, excited molecules and photons makes the plasma very reactive [8], enhancing chemical reactions similarly to the presence of a catalyst [9]. The unique properties of plasma have been employed in many applications such as surface treatments (etching, chemical vapour deposition or thermal spray coatings), metallurgy, sterilization of water and air, medicine (treatment of burns, ulcers or other skin diseases) and many others [8]. Whereas the study of the plasma torch presented herein could be beneficial for its application in various technologies, the author's main interest is on the development of an ATT technology for waste and biomass energy conversion.

One of the advantages of plasma is its high energy density, enabling the design of compact gasification reactors whereby only a short feedstock residence time is required $[6,10]$. Plasma gasification can be applied to a large range of feedstocks such as automobile residues, sludge, asbestos fibres, medical waste, municipal solid waste or refusedderived fuel $[6,10]$. However, one of the challenges for the use of syngas from gasification is the presence of impurities that can damage the downstream electricitygeneration devices. Typical impurities found in syngas, derived from standard gasifiers, are tars, sulphur and chloride compounds [11]. However, in plasma gasifiers, due to the high operational temperatures, tars within the syngas are broken down in situ resulting in a cleaner product gas $[6,9]$. As such, plasma gasification offers a mechanism to reduce the cost and sophistication of syngas cleaning trains compared to that of conventional gasification systems. As a result plasma gasification systems are much more suited for integration with more efficient power generation technologies, such as solid oxide fuel cells (SOFC) achieving high electrical conversion efficiencies of between 55 and $65 \%$ [12].

At present, most plasma gasification systems are based on the use of direct current (DC) plasma torches. DC plasma torches operate by passing a gas, usually air, between two electrodes of high potential difference. This difference causes an arc to form between electrodes, and subsequently ionises the passing gas, creating a plasma. However, the major drawback of using DC torches relates to the lifetime of the electrodes, which will typically need replacing every 200 hours, especially when operated with oxidative gases [10]. A promising alternative is the use of microwaves for 


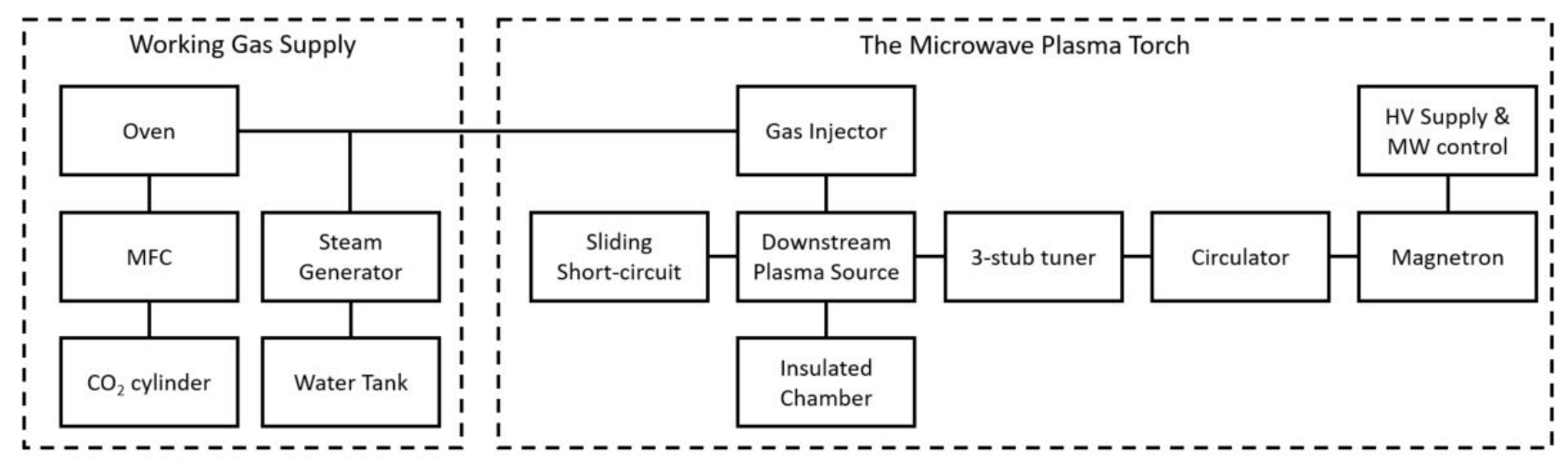

Figure 1: Block diagram of the experimental setup

the generation of plasma, whereby plasma torches can be operated without the requirement of corrodible electrodes.

Microwave plasma has been receiving a growing interest in recent years especially with respect to its applications in ATT $[9,13]$. One of the advantages of microwave plasma, compared to conventional DC systems, is the possibility to operate with a wide range of working gases. ATT experiments using microwave plasma have been reported using $\mathrm{N}_{2}$ [14-16], $\mathrm{Ar}$ [17-19], air [20], $\mathrm{H}_{2} \mathrm{O}$ [21, 22] or $\mathrm{CO}_{2}$ [23], as the ionising gas. $\mathrm{Ar}$ and $\mathrm{N}_{2}$ can be used for pyrolysis treatment, however they are not preferred because they are inert gases that do not directly take part in chemical reactions, whilst the presence of non-combustible $\mathrm{Ar}$ and $\mathrm{N}_{2}$ in the generated pyrolysis gas tends to lower its calorific value and quality [10]. Air has the advantages of being free and brings $\mathrm{O}_{2}$ leading to exothermic oxidation reactions, supplying energy within the reactor while enhancing the carbon conversion rate [22, 24]. On the other hand, excess $\mathrm{O}_{2}$ also causes combustion of combustible gases lowering the generated syngas calorific value [22, 24]. In addition, the $\mathrm{N}_{2}$ content in air dilutes the syngas and lowers its heating value. Microwave plasma is a relatively expensive technology that is expected to generate a very high-quality syngas. $\mathrm{H}_{2} \mathrm{O}$ and $\mathrm{CO}_{2}$ are alternative gases that can have the oxidant role in gasification process. $\mathrm{H}_{2} \mathrm{O}$ is a good candidate as it can generate syngas with a $\mathrm{H}_{2}$ content that can exceed $50 \%$ by volume, and in doing so enhancing the heating value of the syngas [21, 22, 24]. $\mathrm{H}_{2} \mathrm{O}$ is also readily available and could be generated using heat from hot syngas or the exhaust of an electricity generation device. $\mathrm{H}_{2} \mathrm{O}$ has excellent reforming properties that will serve to enhance gasification reactions [5]. Another gas that has preferable chemical activity for gasification applications is $\mathrm{CO}_{2}$, particularly through dry reforming and Boudouard reactions [5]. As such, reintroduction of $\mathrm{CO}_{2}$ rich streams into the gasification reactor, such as the anode exhaust of a SOFC, would not only serve to enhance the gasification process, but also reduce process emissions of $\mathrm{CO}_{2}$ to the atmosphere, mitigating against climate change.

Even though plasma gasification can produce a very clean syngas, the high energy consumption of the plasma torch tends to reduce the overall efficiency of the system and limit its deployment. That is why it is particularly important to have a thorough understanding of the plasma torch capabilities in order to optimise their integration within gasifiers. This study presents the range of operating conditions of which a stable microwave-induced plasma can be generated using $\mathrm{H}_{2} \mathrm{O}$ and $\mathrm{CO}_{2}$. As such this manuscript presents, for the first time, an empirical data set that describes the complete operating envelope of microwave induced plasma using $\mathrm{H}_{2} \mathrm{O}$ and $\mathrm{CO}_{2}$ as the ionisation gases. In addition, the operational temperature of the torches has been recorded within a large chamber yielding critical data to inform the sizing and configuration of a plasma reactor. An insight into the plasma chemistry through optical emission spectroscopy (OES) measurements is also presented, highlighting the presence of active species beneficial for efficient thermal conversion of solid feedstocks.

\section{Materials and Methods}

\subsection{The microwave plasma torch}

Figure 1 presents a schematic diagram of the experimental setup for this study. The main system of the experimental rig is the microwave plasma torch (MPT), comprising of a Downstream plasma source (Sairem SAS, Neyron, France). The microwave generator is a Sairem GMP G4 60K T400 that can generate microwaves at a frequency of $2.45 \mathrm{GHz}$ up to a power of $6 \mathrm{~kW}$. The microwaves propagate through standard WR340 waveguides equipped with a 3 stub-tuner and a sliding short circuit for microwave transmission optimisation. The microwave tuning devices enable the reflected microwave power to be minimized to less than $1 \%$ of the forwarded microwave power whilst maintaining a stable plasma. 

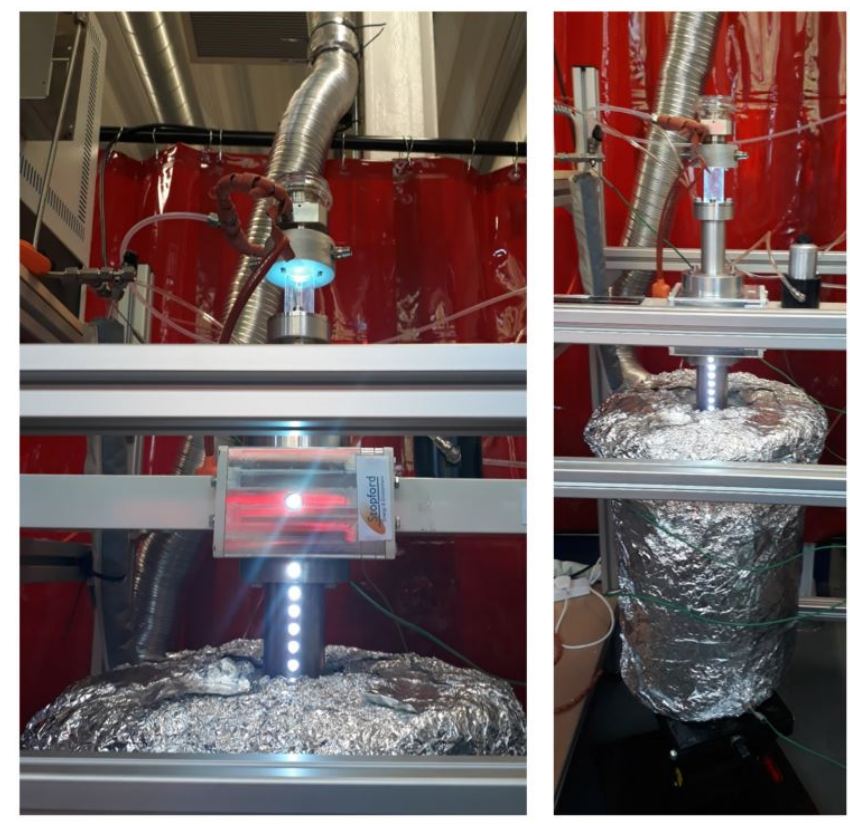

Figure 2: The chimney for OES measurements (left) and the insulated chamber (right) connected to the downstream plasma source in operation with $\mathrm{CO}_{2}$ plasma

The working gas is injected inside a quartz tube $450 \mathrm{~mm}$ long and with an outside and inside diameter of 30 and $25.6 \mathrm{~mm}$ respectively. The working gas flow rate is regulated using a mass flow controller (Alicat Scientific, Tucson AZ, USA) with a maximum capacity of 100 standard litre per minute (SLPM). The working gas can be pre-heated to temperatures exceeding $150^{\circ} \mathrm{C}$ using a high temperature oven. Process $\mathrm{H}_{2} \mathrm{O}$ is generated using an E3000 precision steam generator (Cellkraft, Stockholm, Sweden) operating at flow rates spanning 0.1 to $50 \mathrm{~g} / \mathrm{min}$ at temperatures up to $200^{\circ} \mathrm{C}$. The MPT is manually ignited by inserting a tungsten rod in the quartz tube from the top. For operation of a $\mathrm{H}_{2} \mathrm{O}$ plasma, the working gas is preheated to $>150^{\circ} \mathrm{C}$, enabling $\mathrm{H}_{2} \mathrm{O}$ to be bled into the working gas stream whilst avoiding condensation.

\subsection{Temperature measurements}

An insulated chamber is connected to the bottom chimney of the downstream plasma source as depicted in Figure 2. The chamber is fitted with three thermocouples. The aim of the insulated chamber is twofold, a) to safely capture the exhaust gases and b) to undertake temperature measurements to inform the design of a bespoke ATT reactor. The chamber is of cylindrical construction with a length of $50 \mathrm{~cm}$ and a diameter of $25 \mathrm{~cm}$ corresponding to an inside volume of 24.5 litres. The chamber is insulated with an inside layer of approximately $2 \mathrm{~cm}$ of fire cement on the side and bottom walls, and a $5 \mathrm{~cm}$ layer of fibre wool on the outside. In order to maximise operational temperatures within the chamber, the process exhaust gas outlet is located close to the downstream source on the side of the chamber to increase gas residence time. The thermocouples, named top, middle and bottom, are located across the operational profile of the plasma in order to capture operational temperatures across the plasma plume. The top, middle and bottom thermocouples are located at distances of 20,50 and $70 \mathrm{~cm}$ from the centre of the waveguide, respectively. The top thermocouple is horizontal to the tip of the quartz tube and is not directly exposed to the plasma plume. In addition, the thermocouples protrude $3 \mathrm{~cm}$ into the chamber beyond the refractive lining and measure the temperatures close to the sidewalls. Once the plasma is ignited, the temperatures throughout the chamber are characterised by a rapid increase within the first few minutes, followed by a linear increase to an experimental maxima, which is typically achieved within 1 hour of operation. For example, the temperature at the middle thermocouple for a 20 SLPM $\mathrm{CO}_{2}$ plasma at $3 \mathrm{~kW}$ of microwave power will reach $480^{\circ} \mathrm{C}$ within two minutes after plasma ignition, then taking approximatively 45 minutes to reach a temperature maxima of $630^{\circ} \mathrm{C}$. The experimental temperature maxima is defined when the average temperature increase rate is below $2^{\circ} \mathrm{C}$ per minute over a period of 5 minutes.

\subsection{Optical emission spectroscopy}

Plasma is generated in the Downstream MPT within the quartz tube. As such, a custom-made chimney, $14 \mathrm{~cm}$ long with a series of six holes as presented in Figure 2, was engineered and connected to the lower part of the MPT to enable optical emission spectroscopy (OES) measurements to be taken. The plasma spectra can therefore be measured in seven different locations along the plasma plume at intervals of $0,6,8,9.5,11,12.5$ and $14 \mathrm{~cm}$. The measurement port located at $0 \mathrm{~cm}$ is horizontal to the middle of the waveguide and corresponds to where the plasma is formed, sometimes called the plasma heart. The port located at $6 \mathrm{~cm}$ corresponds to the top of the OES chimney, representing the closest point in which a chamber could be integrated with the MPT. OES measurements were captured using a HR2000+ES spectrometer (Ocean Optics Inc., Largo, FL, USA) measuring in the range 190$1100 \mathrm{~nm}$, with an optical resolution of approximately $0.9 \mathrm{~nm}$ FWHM (Full Width at Half Maximum). A 74-UV collimating lens is used to receive the plasma emissions, which are then transmitted to the spectrometer via optical fibre. Analysis of plasmas spectra and temperature estimations are undertaken by comparing the experimental data with computed data from the software Specair [25].

\section{Results}

\subsection{Operating conditions}

This section presents the operating conditions, including the applied microwave power and the working gas flow rate, for which a stable plasma can be achieved within the experimental MPT unit. However, prior to presenting the results, it is first important to define the vocabulary employed in this section. Firstly, the plasma operation is defined as "steady" when it can be sustained for $>10$ mins without visible flickering of the plume, whereby when in this "steady" state, it is expected to operate for several 
hours without issues. Relating to this, it was empirically determined that the quartz tube starts melting within less than 5 minutes of non-suitable operating conditions. Secondarily, plasma is defined as "unsteady" when the plasma cannot be sustained $>10$ mins. The third definition relates to "no plasma" which describes the conditions where it is not possible to strike or sustain a plasma for more than a few seconds.

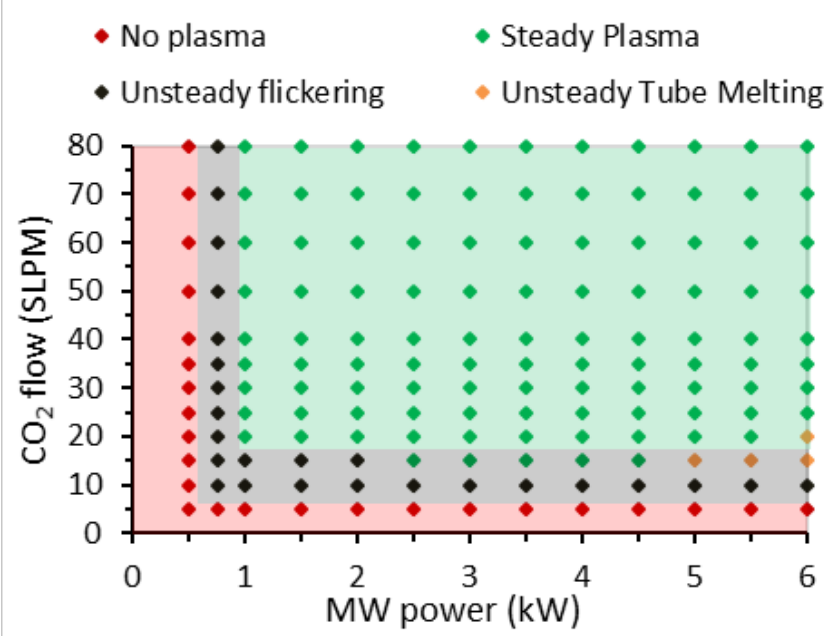

Figure 3: Range of operating conditions for $\mathrm{CO}_{2}$ plasma

The experimentally determined range of operating conditions for the MPT are presented in Figures 3 and 4 for $\mathrm{CO}_{2}$ and $\mathrm{H}_{2} \mathrm{O}$ respectively. A "steady" $\mathrm{CO}_{2}$ plasma can be maintained for flow rates ranging from 20 to at least 80 SLPM at an applied microwave power ranging from 1 to $6 \mathrm{~kW}$. Concerning $\mathrm{H}_{2} \mathrm{O}$ operation, a "steady" plasma can be sustained for flow rates from 20 to at least $50 \mathrm{~g} / \mathrm{min}$ at an applied microwave power ranging between 2.5 and $4 \mathrm{~kW}$. When increasing the applied microwave power over $4 \mathrm{~kW}$, it is necessary to gradually increase the $\mathrm{H}_{2} \mathrm{O}$ flow rate, a minimum $\mathrm{H}_{2} \mathrm{O}$ flow rate of 30 and $40 \mathrm{~g} / \mathrm{min}$ is required at 5 and $6 \mathrm{~kW}$ microwave power respectively, in order to keep a "steady" $\mathrm{H}_{2} \mathrm{O}$ plasma operation.

There are three main reasons causing the plasma to be "unsteady". The first one relates to the gas flow rate. This is particularly true for the $\mathrm{CO}_{2}$ plasma at low flow rates between 10 and 20 SLPM where the plasma is flickering and tends to extinguish randomly. The second reason is that a minimum applied microwave power is required to sustain a stable plasma. It was experimentally determined that a microwave power of $2.5 \mathrm{~kW}$ and $1 \mathrm{~kW}$ were necessary to sustain a pure $\mathrm{H}_{2} \mathrm{O}$ and $\mathrm{CO}_{2}$ plasma, respectively. Below these limits, the plasma plume tends to flicker and randomly extinguishes. No plasma could be formed at a power below $1.75 \mathrm{~kW}$ and $0.75 \mathrm{~kW}$ for pure $\mathrm{H}_{2} \mathrm{O}$ and $\mathrm{CO}_{2}$ respectively. $\mathrm{H}_{2} \mathrm{O}$ requires higher microwave power to stabilise a plasma and this can be attributed to its higher heat capacity compared to $\mathrm{CO}_{2}$. In fact, more energy is required for the $\mathrm{H}_{2} \mathrm{O}$ to reach a certain temperature before the ionization occurs. The third parameter limiting the range of steady plasma operation is the life of the quartz tube. This is especially an issue for the operation of $\mathrm{H}_{2} \mathrm{O}$ plasma. In fact, at low flow rates and high microwave powers, the quartz tube tends to start melting. In Figures 3 and 4, "unsteady" plasma-operating conditions caused by plasma flickering, either due to low gas flow rate or low microwave power, are represented by black points, whereas "unsteady" plasma operation conditions caused by melting of the tube are represented by orange points. The detection of when the quartz tube start melting is verified using OES measurements. It was experimentally determined that the first step of quartz melting is the emission of the Lithium peak at $671 \mathrm{~nm}$ in the plasma that can also be visualized through glowing red points in the quartz tube. Lithium is one of the common impurities in quartz tube and exhibits a strong emission peak at $671 \mathrm{~nm}$ when heated. This is the main issue encountered at low $\mathrm{H}_{2} \mathrm{O}$ flow rates. For microwave powers above $4 \mathrm{~kW}$, it is necessary to gradually increase the $\mathrm{H}_{2} \mathrm{O}$ flow rate when increasing the microwave power in order to protect the quartz tube. On the other hand, high working gas flow rate operation is possible and no higher limitations were found in the working range of the experimental set up (maximum flow of $100 \mathrm{SLPM}$ for $\mathrm{CO}_{2}$ and $50 \mathrm{~g} / \mathrm{min}$ for $\mathrm{H}_{2} \mathrm{O}$ ). Operation of the MPT using mixtures of $\mathrm{CO}_{2}$ and $\mathrm{H}_{2} \mathrm{O}$ has also been tested by the authors and is possible over a wide range of operating conditions, but these results are not presented here. Generally, steady plasma operation is possible when adding $\mathrm{CO}_{2}$ to stable pure $\mathrm{H}_{2} \mathrm{O}$ plasma or when adding $\mathrm{H}_{2} \mathrm{O}$ to a steady pure $\mathrm{CO}_{2}$ operating plasma.

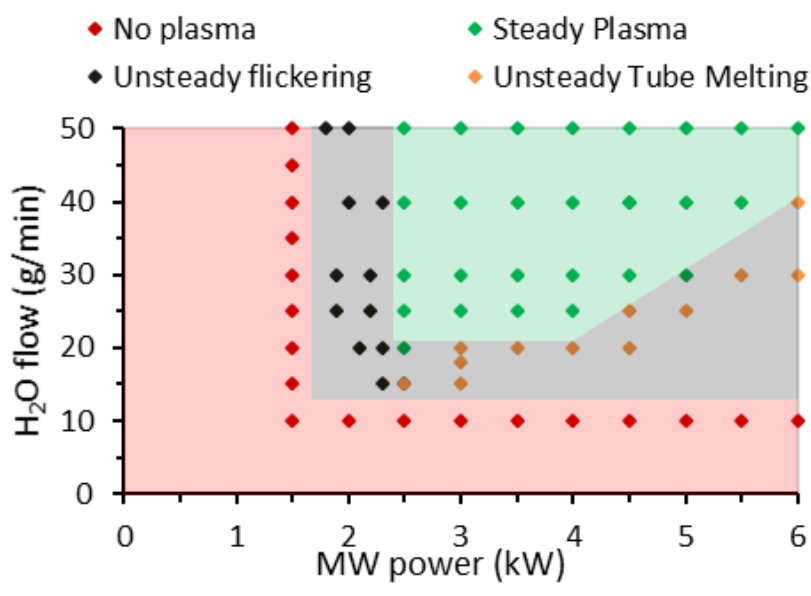

Figure 4: Range of operating conditions for $\mathrm{H}_{2} \mathrm{O}$ plasma

\subsection{Temperature measurements}

Gasification is a thermal process and hence it is critical to maintain a sufficient temperature within the gasification chamber to enable reactions to proceed. In order to investigate the suitability of the MPT for its integration in an ATT system, the achievable temperature maximas within the chamber were recorded for $\mathrm{CO}_{2}$ and $\mathrm{H}_{2} \mathrm{O}$ 
plasmas, varying flow rates and magnetron powers across the steady operating conditions presented in section 3.1.

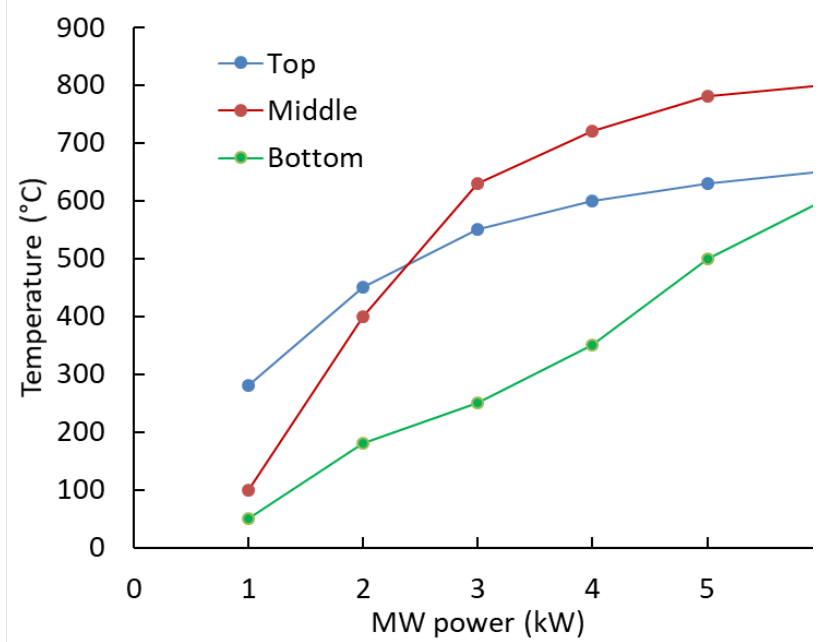

Figure 5: Temperature recorded in chamber with $20 \mathrm{SLPMCO}_{2}$ plasma varying the applied microwave power

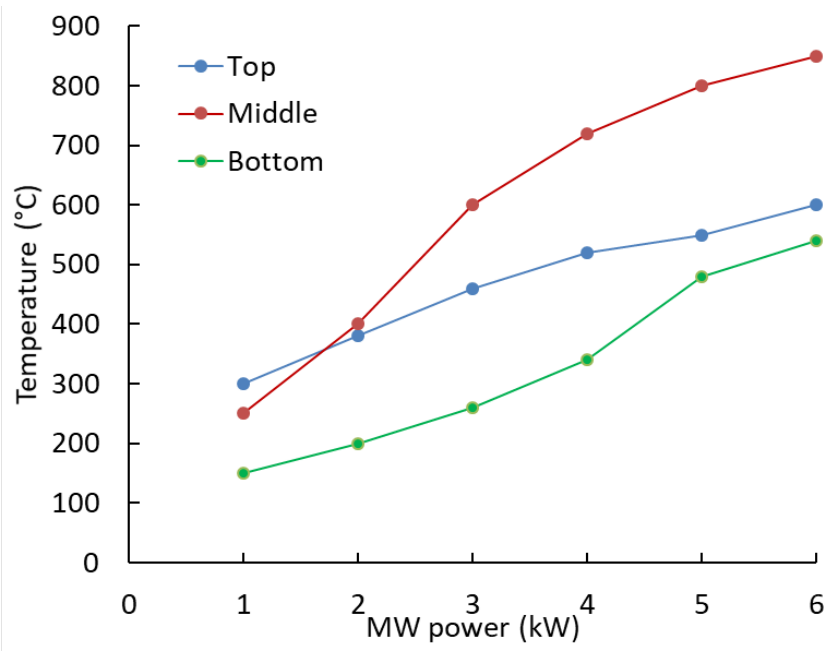

Figure 6: Temperature recorded in chamber with $40 \mathrm{SLPM} \mathrm{CO}_{2}$ plasma varying the applied microwave power

Figure 5 presents the temperatures recorded when operating a $\mathrm{CO}_{2}$ plasma across magnetron powers ranging from 1 to $6 \mathrm{~kW}$ at a working gas flow rate of 20 SLPM, whilst Figure 6 presents similar data whereby the working gas flow rate has been increased to 40 SLPM. For a $\mathrm{CO}_{2}$ plasma, temperatures of between 50 and $800^{\circ} \mathrm{C}$ have been recorded at a working gas flow rate of 20 SLPM whereas temperatures of between 150 and $850^{\circ} \mathrm{C}$ were obtained at higher flow rate of 40 SLPM. The temperature is clearly increasing when increasing the applied microwave power, especially in the middle of the chamber. At microwave powers of $>2 \mathrm{~kW}$, the highest operating temperatures were achieved in the middle of the chamber, whilst at microwave powers of $<2 \mathrm{~kW}$ the highest temperatures were recorded at the top of the chamber. It is important to remind the reader that the top thermocouple is located horizontally next to the tip of the quartz tube and is therefore not directly exposed to the plasma plume. As such, the top thermocouple provides a temperature estimation of the gas leaving the chamber. As presented in Figure 6, an increase $\mathrm{CO}_{2}$ flow rate results in a slightly lower average temperature at the top and bottom of the chamber that can be explained by a heat dilution effect. On the other hand, an increase $\mathrm{CO}_{2}$ flow rate also results in an increase temperature of the middle thermocouple, from $800^{\circ} \mathrm{C}$ at $20 \mathrm{SLPM}$ to $850^{\circ} \mathrm{C}$ at $40 \mathrm{SLPM}$ and both at $6 \mathrm{~kW}$ microwave power, suggesting an extension of the plasma plume closer to the middle thermocouple. Through comparison of Figure 5 and 6 , it is evident that the microwave power has a greater effect on the temperature generated within the chamber than the working gas flow rate.

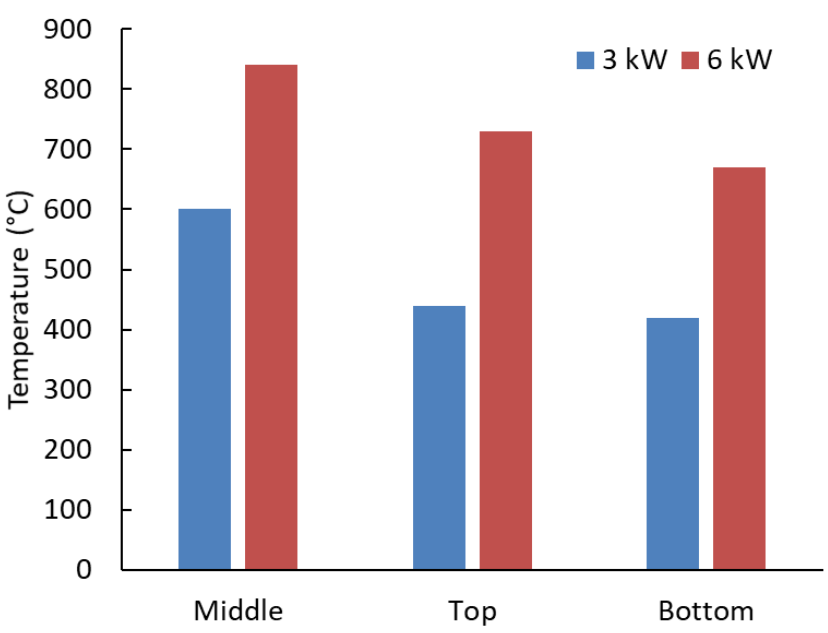

Figure 7: Temperature recorded in chamber with $50 \mathrm{~g} / \mathrm{min} \mathrm{H}_{2} \mathrm{O}$ plasma at applied microwave power of 3 and $6 \mathrm{~kW}$

Figure 7 presents the temperatures recorded in the chamber with $50 \mathrm{~g} / \mathrm{min}_{2} \mathrm{O}$ plasma for microwave powers of 3 and $6 \mathrm{~kW}$. The temperature measurements with $\mathrm{H}_{2} \mathrm{O}$ plasmas are only presented for working gas flow rates of $50 \mathrm{~g} / \mathrm{min}$ as it was empirically determined that the effect of the flow rate was very low, with temperatures achieved at a flow rate of $25 \mathrm{~g} / \mathrm{min}$ being similar to those achieved at $50 \mathrm{~g} / \mathrm{min}$. At microwave powers of 3 and $6 \mathrm{~kW}$, the maximum chamber temperatures achieved were $600^{\circ} \mathrm{C}$ and $800^{\circ} \mathrm{C}$ respectively. As such, the temperature maximas achieved for $\mathrm{H}_{2} \mathrm{O}$ plasmas are very similar to those achieved with $\mathrm{CO}_{2}$. However, the temperature difference within the chamber is lower for $\mathrm{H}_{2} \mathrm{O}$ than for $\mathrm{CO}_{2}$. This can be attributed to the higher gas flow rates required to operate $\mathrm{H}_{2} \mathrm{O}$ plasmas, making more homogeneous temperatures explained by greater turbulence within the reactor chamber. 


\subsection{Plasma chemistry}

One of the advantages of plasma is its high chemical activity that will enhance gasification reactions rates avoiding the need for a catalyst [9]. In this study, an insight into the $\mathrm{CO}_{2}$ and $\mathrm{H}_{2} \mathrm{O}$ plasma chemistry is given using optical emission spectroscopy (OES). OES measurements of pure $\mathrm{CO}_{2}$ and pure $\mathrm{H}_{2} \mathrm{O}$ plasma are presented, providing information on the chemical species present in the plasma as well as information on the plasma temperatures. The aim of this study was to elucidate the active species present along the plasma plume.

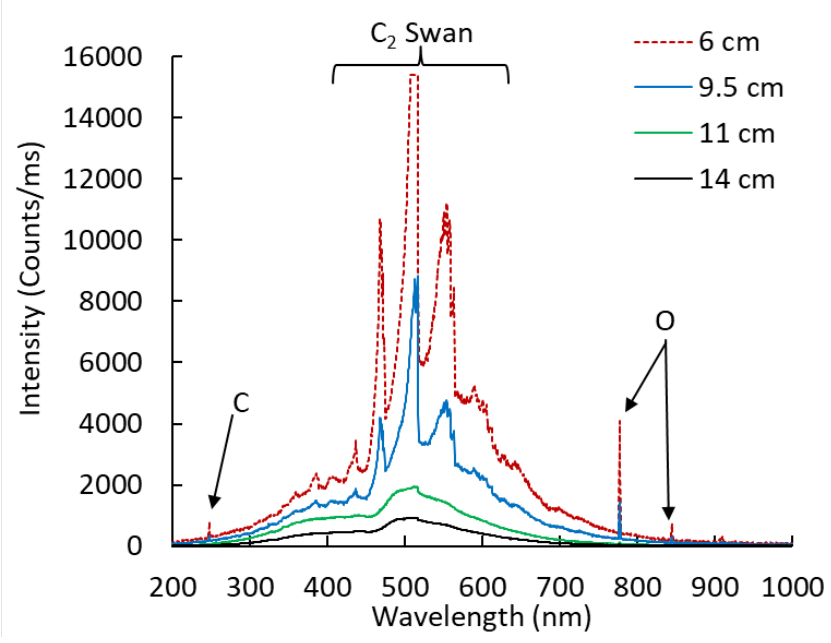

Figure 8: $\mathrm{CO}_{2}$ plasma spectra at $20 \mathrm{SLPM}$ and $3 \mathrm{~kW}$ microwave power along the plasma

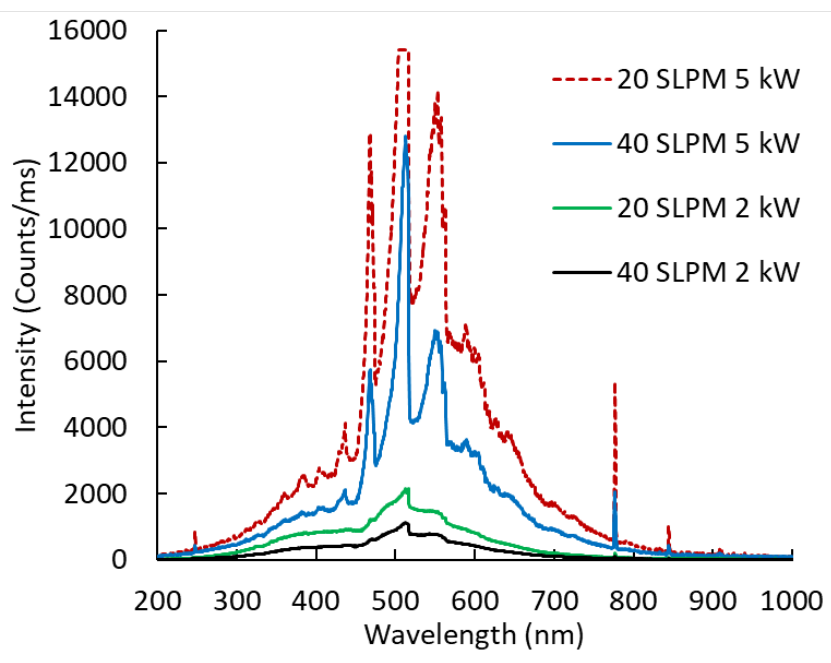

Figure 9: $\mathrm{CO}_{2}$ plasma spectra varying the gas flow rate and microwave power $8 \mathrm{~cm}$ downstream of plasma heart

Figure 8 presents the emissions observed along a $\mathrm{CO}_{2}$ plasma generated using a working gas flow rate of 20 SLPM at a microwave power of $3 \mathrm{~kW}$. The $\mathrm{C}_{2}$ Swan band is the dominant emissions from the $\mathrm{CO}_{2}$ plasma, corresponding to the wavelength range of 400 to $600 \mathrm{~nm}$. This wavelength range represents blue light in the visible light wavelength spectrum explaining the blue colour of the $\mathrm{CO}_{2}$ plasma plume as presented in Figure 2. The O peaks are also present in the infrared wavelength range at 777 and $844 \mathrm{~nm}$ whereas the C peak is observed in the ultraviolet range at $248 \mathrm{~nm}$. The presence of the $\mathrm{C}_{2}, \mathrm{C}$ and $\mathrm{O}$ emissions illustrates the dissociation of $\mathrm{CO}_{2}$ in the plasma. In fact, in the high temperature plasma, $\mathrm{CO}_{2}$ tends to dissociate through the following reaction: $\mathrm{CO}_{2} \rightarrow \mathrm{CO}+\mathrm{O}$ but then recombines to $\mathrm{CO}_{2}$ when the temperature decreases [23, 26-29]. The dissociation and recombination mechanisms are complex and involve many reactions with the dominant species being $\mathrm{C}, \mathrm{O}, \mathrm{CO}, \mathrm{C}_{2}, \mathrm{O}_{2}$ and $\mathrm{CO}_{2}$. Details of those mechanisms can be found in the literature [26-29].

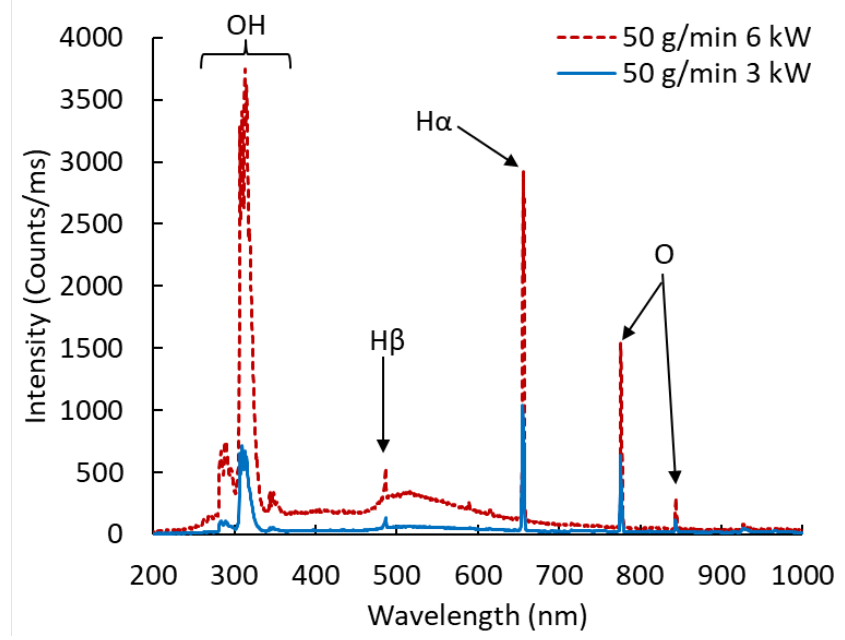

Figure 10: $\mathrm{H}_{2} \mathrm{O}$ plasma spectra at $50 \mathrm{~g} / \mathrm{min}$ and $6 \mathrm{~cm}$ downstream of the plasma heart for microwave power of 3 and $6 \mathrm{~kW}$

According to Figure 8, it is evident that the intensity of the emissions are decreasing along the length of the plasma corresponding to lower temperature and species concentration. However, the $\mathrm{C}_{2}$ Swan band and the O peaks can always be identified in $\mathrm{CO}_{2}$ plasmas even $14 \mathrm{~cm}$ down from the centre of the waveguide in any operating conditions, whereas the $\mathrm{C}$ peak tends to disappear at lower plasma intensities. Figure 9 presents the influence of the microwave power and the $\mathrm{CO}_{2}$ flow rate on the plasma emissions. It is clear that an increase of the microwave power and a decrease of the working gas flow rate results in higher emissions intensities. However, a variation in the applied microwave power has more effect on the plasma spectra than varying the working gas flow rate. $\mathrm{CO}_{2}$ plasma is very bright and the high emission intensities result in spectrometer saturation at approximately 15,000 counts $/ \mathrm{ms}$ as observed in Figures 8 and 8 respectively. Spectrometer saturation generally occurs close to the $\mathrm{CO}_{2}$ plasma heart and up to $8 \mathrm{~cm}$ down the plasma plume as can be seen in Figure 9. 
Figure 10 presents the typical OES measurements of a pure $\mathrm{H}_{2} \mathrm{O}$ plasma. An increase in microwave power results in higher $\mathrm{H}_{2} \mathrm{O}$ emission intensities, reflecting the higher temperatures and concentrations of chemical species. However, this study served to identify that for $\mathrm{H}_{2} \mathrm{O}$ plasmas the working gas flow rate has a negligible impact on the emission intensities. The $\mathrm{H}_{2} \mathrm{O}$ plasma spectra is marked by the presence of mainly three species, which are $\bullet \mathrm{OH}, \cdot \mathrm{H}$ and $\bullet \mathrm{O}$. The $\mathrm{OH}$ ion emits in the UV range between 275 and $340 \mathrm{~nm}$ with its main peak being at $309 \mathrm{~nm}$. Emissions from hydrogen atoms are identified at 656 and $486 \mathrm{~nm}$, respectively corresponding to the $\mathrm{H} \alpha$ and $\mathrm{H} \beta$ transitions. The hydrogen atom excited to the level $n=3$ tends to come back to the less excited state $n=2$ with the emission of a photon at the wavelength $656 \mathrm{~nm}$, corresponding to the $\mathrm{H \alpha}$ transition. Whereas the $\mathrm{H} \beta$ is the transition between the higher excited state of $n=4$ to $n=2$. The $H \alpha$ and $H \beta$ transitions are the only ones identified in experimental results from the Balmer series. The $\mathrm{H} \alpha$ is the dominant emission, also responsible for the orange-red colour of the $\mathrm{H}_{2} \mathrm{O}$ plasma, whereas $\mathrm{H} \beta$ has a lower intensity and tends to disappear with decreasing the forward microwave power or as you transition along the plasma plume. The $\bullet \mathrm{O}$ peaks at 777 and $844 \mathrm{~nm}$ are also present, similar to that of the $\mathrm{CO}_{2}$ plasma. The presence of the $\bullet \mathrm{OH}, \bullet \mathrm{H}$ and $\bullet \mathrm{O}$ peaks is indicative of the dissociation of $\mathrm{H}_{2} \mathrm{O}$ in plasma. In fact, similarly to $\mathrm{CO}_{2}, \mathrm{H}_{2} \mathrm{O}$ dissociates at high plasma temperatures predominately through the reaction: $\mathrm{H}_{2} \mathrm{O} \rightarrow \mathrm{OH}+\mathrm{H}$ prior to recombining as temperatures decrease [30]. The $\mathrm{H}_{2} \mathrm{O}$ dissociation and recombination mechanisms are complex and mainly involve the dominant species $\bullet \mathrm{H}, \bullet \mathrm{OH}, \mathrm{H}_{2}, \mathrm{O}_{2}$ and $\mathrm{H}_{2} \mathrm{O}[30]$.

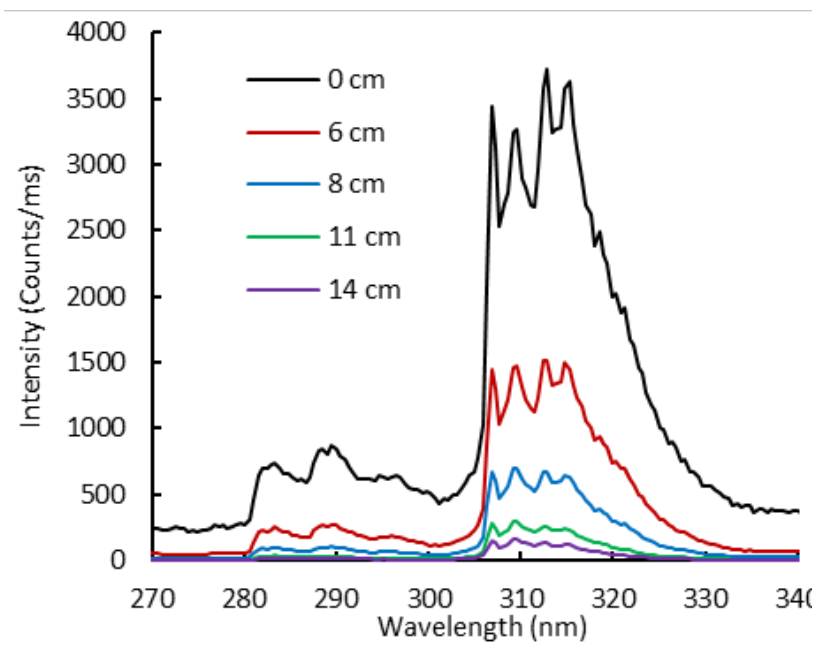

Figure 11: Comparison of $\mathrm{OH}$ emissions along the plasma for $\mathrm{H}_{2} \mathrm{O}$ plasma at $25 \mathrm{~g} / \mathrm{min}$ and $4 \mathrm{~kW}$ microwave power

Figure 11 presents the $\bullet \mathrm{OH}$ emissions measured at several distances from the plasma heart which are characterised by a decrease in intensity and change in shape of the $\bullet \mathrm{OH}$ emission along the transect of the plasma. The study served to identify that the $\bullet \mathrm{OH}$ emissions are still present in $\mathrm{H}_{2} \mathrm{O}$ plasmas under any operating conditions up to $14 \mathrm{~cm}$ away from the centre of the waveguide, albeit at lower intensities.

The comparison of the $\bullet \mathrm{OH}$ emissions with simulated spectra using the software Specair was carried out in order to estimate the plasma temperature, along the plasma plume transect, at varying operating conditions. The temperature estimations calculated by Specair are based upon rotational temperatures of the identified molecules. Importantly, for this study, it has previously been determined that $\mathrm{CO}_{2}$ and $\mathrm{H}_{2} \mathrm{O}$ microwave plasmas are in local thermal equilibrium, meaning that the gas temperature is estimated to be equal to that of species rotational temperatures [23, 26-28, 30]. Figure 12 presents an example of an experimental spectrum fit using the Specair software. This was repeated for $\mathrm{H}_{2} \mathrm{O}$ and $\mathrm{CO}_{2}$ $\left(1 \mathrm{~g} / \mathrm{min} \mathrm{H}_{2} \mathrm{O}\right.$ was added in $\mathrm{CO}_{2}$ to study the $\cdot \mathrm{OH}$ emissions) plasmas along the quartz tube, at vary applied microwave powers and working gas flow rates. This data indicated that the temperature in pure $\mathrm{H}_{2} \mathrm{O}$ plasma varies from $5,800^{\circ} \mathrm{C}$ in the heart of the plasma to $2,300^{\circ} \mathrm{C} 14 \mathrm{~cm}$ down the quartz tube. In contrast, higher temperatures were indicated for $\mathrm{CO}_{2}$ with maximum observed temperature estimated to be $6,300^{\circ} \mathrm{C}$. This study also served to identify that the temperature of the plasma plume could be varied by up to $500^{\circ} \mathrm{C}$ by varying the forward microwave power and the working gas flow rate. Furthermore, by increasing the microwave power or by decreasing the working gas flow rate, the diameter of the plasma plume is increased, reflecting an increase in energy density, favouring additional molecular ionization, rather than an increase of the plasma temperature. These results demonstrate that very active ions $(\bullet \mathrm{OH}, \bullet \mathrm{O}, \bullet \mathrm{H})$ are still present at relatively high temperatures in the quartz tube up to $14 \mathrm{~cm}$ down the centre of the waveguide.

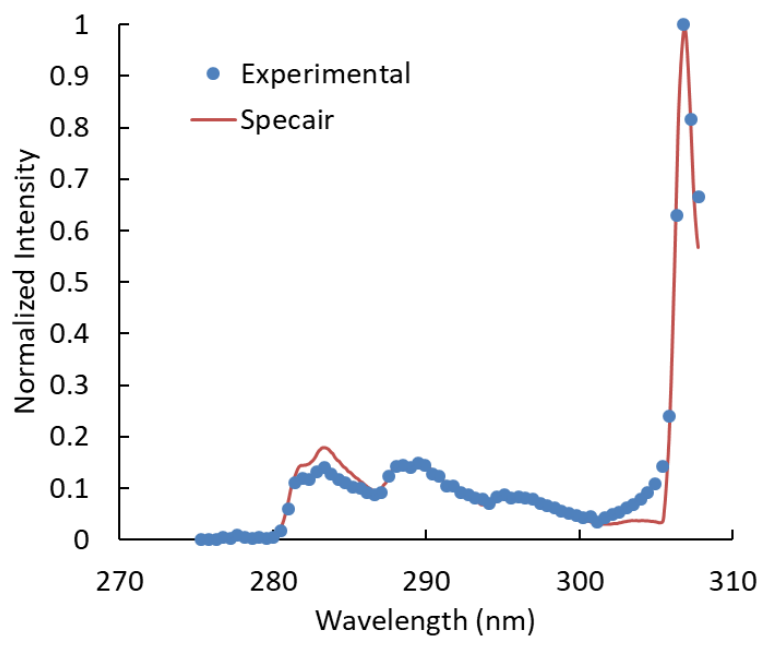

Figure 12: Fit of experimental OH spectra using Specair for a pure $\mathrm{H}_{2} \mathrm{O}$ flow of $20 \mathrm{~g} / \mathrm{min}$, an applied microwave power of $3 \mathrm{~kW}, 6 \mathrm{~cm}$ downstream of the plasma heart, the plasma temperature estimation is $4356{ }^{\circ} \mathrm{C}$ 


\section{Discussion}

This section provides a discussion based on the experimental results presented in section 3 , with emphasis on the application of the MPT into a gasification system for waste or biomass conversion.

The operating temperatures in gasifiers generally vary between $550^{\circ} \mathrm{C}$ and $1,600^{\circ} \mathrm{C}$ according to the reactor design, the working gas and the feedstock characteristics [5]. Temperatures $>600^{\circ} \mathrm{C}$ are typically required for methane and hydrocarbon decomposition into $\mathrm{CO}$ and $\mathrm{H}_{2}$, the main components of syngas [5]. However, in this study, the maximum temperature recorded at the bottom of the connected chamber was $600^{\circ} \mathrm{C}$ at a maximum operational microwave power of $6 \mathrm{~kW}$. Given that extremely high operating temperatures of $>2,000^{\circ} \mathrm{C}$ have been observed in the MPT plume, the significantly lower temperatures measured in the bottom of the chamber illustrates the requirement for compact plasma gasification reactor integration to avoid steep thermal gradients across the system. The injection of air or oxygen into a gasification vessel could also be used to increase the reaction temperature through exothermic oxidation reactions. However, the use of air or $\mathrm{O}_{2}$ for this process would result in a reduced syngas calorific value due to fuel oxidation and $\mathrm{N}_{2}$ dilution. The study serves to demonstrate how the manipulation of MPT operating parameters could be used to rapidly regulate the temperature within a gasification reactor, which in turn can be used to maximise the efficiency of the gasification process. Whereas the applied microwave power is directly proportional to the temperature in the chamber, the flow of working gas can be tuned to optimise the quantity of reactant required for feedstock conversion.

One of the main advantages of using plasma in ATT processes is the quality of the syngas generated, reducing the requirement for clean-up prior to its use in power generation [6]. In fact, this study highlights plasma temperatures ranging from $2,000^{\circ} \mathrm{C}$ to $6,300^{\circ} \mathrm{C}$ within the first $14 \mathrm{~cm}$ of the plasma plume, which is appropriate for tars dissociation which occurs at temperatures of $>1,000^{\circ} \mathrm{C}$ [5]. In addition, the presence of ions, electrons, excited molecules and photons within plasma should also serve to enhance the chemical reactions, including gasification reactions as well as tars conversion [8]. The very active $\bullet \mathrm{O}$ and $\bullet \mathrm{OH}$ identified in plasma will take part in chemical reactions thus improving solid conversion and syngas reforming. Furthermore, the consumption of $\bullet \mathrm{O}$ and $\bullet \mathrm{OH}$ in gasification reactions will prevent $\mathrm{CO}_{2}$ and $\mathrm{H}_{2} \mathrm{O}$ recombination, resulting in the generation of additional $\mathrm{CO}$ and $\mathrm{H}_{2}$, which in turn enhances the quality of the resultant syngas. The benefit of $\mathrm{H}_{2} \mathrm{O}$ and $\mathrm{CO}_{2}$ plasma chemistry is therefore twofold as it a) provides very chemically active species enhancing gasification reactions and $b$ ) generates additional $\mathrm{CO}$ and $\mathrm{H}_{2}$ from $\mathrm{CO}_{2}$ and $\mathrm{H}_{2} \mathrm{O}$ dissociation respectively. As such, these processes are in theory able to enhance the energy in the syngas to exceed that of the initial energy content of the solid feedstock, assuming complete conversion and additional $\mathrm{CO}$ or $\mathrm{H}_{2}$ generated from the plasma working gas dissociation.

Nevertheless, the exceptional properties of plasma can only be efficiently exploited if the solid and the gas resulting from its devolatilization have sufficient time in contact with plasma. In fact, studies integrating MPT in gasification reactors at laboratory scale generally operate through the injection of powdered feedstock within the plasma plume $[21,22,24,31]$ or from the top of the quartz tube [20]. These plasma entrained-flow bed configurations result in low feedstock conversion efficiency, because of the short feedstock residence time, despite the contact with the plasma at high temperatures. The design of a gasification reactor integrated with the MPT is one of the main challenges to improve the efficiency of the process. The experimental study of the MPT, described here, provides useful parametric data to inform the design of a microwave plasma ATT reactor. The plasma moving-bed reactor such as described in Tang et al. [10] is an alternative that could improve feedstock conversion efficiencies as well as the syngas quality. The reactor could be connected, effectively replacing the OES chimney $6 \mathrm{~cm}$ down the plasma heart, where the plasma temperature is still $>4,000^{\circ} \mathrm{C}$. This would enable the solid feedstock to be thermally dissociated at the bottom of the chamber whereas the resultant syngas would go through the high temperature plasma to exit at the top of the reactor, enhancing gas reforming and tars dissociation. Further gas reforming could be achieved by recycling part of the generated syngas in the plasma working gas, which has been proved very efficient for tars reforming [32].

Whereas plasma properties are ideal for gasification applications, the main drawback is the energy consumption of the plasma torch that tends to lower the overall efficiency of the process. The gasification efficiency is generally estimated by the cold gas efficiency, which is defined by the energy in the syngas generated divided by the energy content of the feedstock. In case of allothermal gasification using a plasma torch, the energy consumption of the plasma torch is added to the feedstock energy in the denominator. Conventional authothermal gasification efficiencies are generally circa $80 \%$ [33]. Considering a $90 \%$ feedstock conversion when using plasma (the energy in syngas is then assumed equal to $90 \%$ of the energy content of the feedstock), the energy consumed by the plasma torch should then be less than $12.5 \%$ of the energy content of the feedstock in order to achieve similar cold gas efficiencies as conventional gasification. For example, a $5 \mathrm{~kW}$ plasma torch should be able to treat at least $40 \mathrm{~kW}$ of feedstock, corresponding to a feed rate of $9.6 \mathrm{~kg} / \mathrm{hr}$ of woody biomass or $4.2 \mathrm{~kg} / \mathrm{hr}$ of plastic (assuming woody biomass and plastic heating values of 15 and $34 \mathrm{MJ} / \mathrm{kg}$, respectively [33]). With respect to power generation through an integrated gasification power plant, the clean, low tar syngas generated when using plasmas can enable 
higher net electrical efficiencies to be achieved, compared to that of autothermal gasification [6]. This observation is further reinforced by the emergence of SOFC systems, that enable greater efficiencies to be achieved by converting syngas to electricity through electrochemical reactions [12].

\section{Conclusion}

Waste management and energy generation are two major challenges of the $21^{\text {st }}$ century for the mitigation of climate change. This study investigates the feasibility of integrating a MPT in a gasification system to create an innovative energy from waste or biomass solution. The MPT can be operated in a wide range of operating conditions, including flow rates ranging 20 to 80 SLPM and forward microwave powers of between 1 to $6 \mathrm{~kW}$ for pure $\mathrm{CO}_{2}$, and flow rates of 25 to $50 \mathrm{~g} / \mathrm{min}$ and forward microwave powers of 2.5 to $6 \mathrm{~kW}$ for pure $\mathrm{H}_{2} \mathrm{O}$. Experimental studies have served to prove the flexibility of the device, with respect to operating parameters and temperature control, which is a great advantage for its integration in a gasification system. Temperatures up to $850^{\circ} \mathrm{C}$ have been measured in a large chamber connected to the plasma torch providing valuable information for the design of an integrated gasification system and showing the benefit of a compact reactor. An insight into the plasma chemistry has been obtained through OES measurements showing the dissociation of $\mathrm{H}_{2} \mathrm{O}$ and $\mathrm{CO}_{2}$ molecules at high temperature up to $6,300^{\circ} \mathrm{C}$. Very reactive species such as $\bullet \mathrm{O}$ and $\bullet \mathrm{OH}$ are formed and are present in the plasma plume even $14 \mathrm{~cm}$ downstream of the plasma heart. Those species will enhance gasification reactions whereas additional $\mathrm{CO}$ and $\mathrm{H}_{2}$ will enrich the syngas from $\mathrm{CO}_{2}$ and $\mathrm{H}_{2} \mathrm{O}$ dissociation respectively. The MPT provides an ideal environment for gasification with high temperature and very reactive chemical species. The integration of microwave plasma in gasification has promising potential for the generation of high-quality syngas that lowers the requirement for gas cleaning and eases the coupling of high efficiency energy conversion devices such as SOFC.

\section{Acknowledgements}

This work was supported by the European Regional Development Fund (ERDF) through the Centre for Global Eco-Innovation (CGE) in partnership between Lancaster University and Stopford Projects Ltd. This research was also supported by Innovate UK through the grant number 133710.

\section{References}

[1] IPCC. Climate Change 2014: Synthesis Report, https://www.ipcc.ch/report/ar5/syr/; 2014 [accessed 20 March 2020].

[2] Kaza S, Yao L, Bhada-Tata P, Van Woerden F. What a Waste 2.0: A Global Snapshot of Solid Waste Management to 2050 . 2018 . https://doi.org/10.1596/978-1-4648-1329-0
[3] The European Parliament and the Council of the European Union. Directive 2008/98/EC of the European Parliament and of the Council of 19 November 2008 on waste and repealing certain Directives, https://eur-lex.europa.eu/legalcontent/EN/TXT/?uri=celex\%3A32008L0098; 2008 [accessed 20 March 2020].

[4] The European Parliament and the Council of the European Union. Directive 2018/851 of the European Parliament and of the Council of 30 May 2018 amending Directive 2008/98/EC on waste, https://eurlex.europa.eu/legalcontent/EN/TXT/?uri=celex:32018L0851; 2018 [accessed 20 March 2020].

[5] Arena U. Process and technological aspects of municipal solid waste gasification: A review. Waste Management 2012;32:625-639. https://doi.org/10.1016/j.wasman.2011.09.025

[6] Fabry F, Rehmet C, Rohani V, Fulcheri L. Waste Gasification by Thermal Plasma: A Review. Waste and Biomass Valorization 2013;4:421-439. https://doi.org/10.1007/s12649-013-9201-7

[7] Ruj B, Ghosh S. Technological aspects for thermal plasma treatment of municipal solid waste - A review. Fuel Processing Technology 2014;126:298-308. https://doi.org/10.1016/j.fuproc.2014.05.011

[8] Fridman A. Plasma Chemistry. Cambridge: Cambridge University Press 2008. https://doi.org/10.1017/CBO9780511546075

[9] Ho GS, Faizal HM, Ani FN. Microwave induced plasma for solid fuels and waste processing: A review on affecting factors and performance criteria. Waste Management 2017;69:423-430. https://doi.org/10.1016/j.wasman.2017.08.015

[10] Tang L, Huang H, Hao H, Zhao K. Development of plasma pyrolysis/gasification systems for energy efficient and environmentally sound waste disposal. Journal of Electrostatics 2013;71:839. https://doi.org/10.1016/j.elstat.2013.06.007

[11] Aravind PV, De Jong W. Evaluation of high temperature gas cleaning options for biomass gasification product gas for Solid Oxide Fuel Cells. Progress in Energy and Combustion Science 2012;38:737-764.

https://doi.org/10.1016/j.pecs.2012.03.006

[12] Sharaf O, Orhan M. An overview of fuel cell technology: Fundamentals and applications. Renewable and Sustainable Energy Reviews 2014;32:810-853. https://doi.org/10.1016/j.rser.2014.01.012

[13] Sanlisoy A, Carpinlioglu M. A review on plasma gasification for solid waste disposal. International Journal of Hydrogen Energy 2017;42:1361-1365. https://doi.org/10.1016/j.ijhydene.2016.06.008

[14] Lin K, Lin Y, Hsiao Y. Microwave plasma studies of Spirulina algae pyrolysis with relevance to hydrogen production. Energy 2013;64:567-574. https://doi.org/10.1016/j.energy.2013.09.055 
[15] Lin Y, Wu T, Jhang S, Yang P, Hsiao Y. Hydrogen production from banyan leaves using an atmosphericpressure microwave plasma reactor. Bioresource Technology 2014;161:304-309. https://doi.org/10.1016/j.biortech.2014.03.067

[16] Lin Y, Wu T, Liu W, Hsiao Y. Production of hydrogen from rice straw using microwave-induced pyrolysis. Fuel 2014;119:21-26. https://doi.org/10.1016/j.fuel.2013.11.046

[17] Khongkrapan P, Thanompongchart P, Tippayawong $\mathrm{N}$, Kiatsiriroat T. Microwave plasma assisted pyrolysis of refuse derived fuels. Central European Journal of Engineering 2014;4:72-79. https://doi.org/10.2478/s13531-013-0142-5

[18] Lupa C, Wylie S, Shaw A, Sweetman A, Herbert B, Experimental analysis of biomass pyrolysis using microwave-induced plasma. Fuel Processing technology 2012;97:79-84. https://doi.org/10.1016/j.fuproc.2012.01.015

[19] Lupa C, Wylie S, Shaw A, Sweetman A, Herbert B. Gas evolution and syngas heating value from advanced thermal treatment of waste using microwave-induced plasma. Renewable Energy 2013;50:1065-1072 https://doi.org/10.1016/j.renene.2012.09.006

[20] Sturm G, Munoz A, Aravind P, Stefanidis G. Microwave-Driven Plasma Gasification for Biomass Waste Treatment at Miniature Scale. IEEE Transactions on Plasma Science 2016;44:670-678. https://doi.org/10.1109/TPS.2016.2533363

[21] Shin D, Hong Y, Lee S, Kim Y, Cho C, Ma S, Chun $\mathrm{S}$, Lee B, Uhm H. A pure steam microwave plasma torch: Gasification of powdered coal in the plasma. Surface \& Coatings Technology 2013;228:520-523. https://doi.org/10.1016/j.surfcoat.2012.04.071

[22] Yoon S, Lee S. Hydrogen-rich syngas production through coal and charcoal gasification using microwave steam and air plasma torch. International Journal of Hydrogen Energy 2012;37:17093-17100. https://doi.org/10.1016/j.ijhydene.2012.08.054

[23] Uhm H, Kwak H, Hong Y. Carbon dioxide elimination and regeneration of resources in a microwave plasma torch. Environmental Pollution 2017;211:191-197. https://doi.org/10.1016/j.envpol.2015.12.053b

[24] Hong Y, Lee S, Shin D, Kim Y, Lee B, Cho S, Chang $H$. Syngas production from gasification of brown coal in a microwave torch plasma. Energy 2012;47:36-40, https://doi.org/10.1016/j.energy.2012.05.008

[25] SpectralFit S.A.S. Specair. http://www.specairradiation.net/ [accessed 20 March 2020].

[26] Sun H, Lee J, Do H, Im S, Soo Bak M. Experimental and numerical studies on carbon dioxide decomposition in atmospheric electrodeless microwave plasmas. Journal of Applied Physics 2017;122. https://doi.org/10.1063/1.4994008

[27] Berthelot A, Bogaerts A. Modeling of CO2 Splitting in a Microwave Plasma: How to Improve the Conversion and Energy Efficiency. J. Phys. Chem. C
2017;121:8236-8251

https://doi.org/10.1021/acs.jpcc.6b12840

[28] Kwak H, Uhm H, Hong Y, Choi E. Disintegration of Carbon Dioxide Molecules in a Microwave Plasma Torch. Scientific Reports 2015;5. https://doi.org/10.1038/srep18436

[29] Qin Y, Niu G, Wang X, Luo D, Duan Y. Status of CO2 conversion using microwave plasma. Journal of $\mathrm{CO} 2$ Utilization https://doi.org/10.1016/j.jcou.2018.10.003

[30] Uhm H, Kim J, Hong Y. Disintegration of water molecules in a steam-plasma torch powered by microwaves. Physics of Plasmas 2007;14. https://doi.org/10.1063/1.2749225

[31] Yoon S, Lee J. Syngas production from coal through microwave plasma gasification: Influence of oxygen, steam, and coal particle size. Energy and Fuels 2012;26:524-529. https://doi.org/10.1021/ef2013584

[32] Saleem F, Harris J, Zhang K, Harvey A. Non-thermal plasma as a promising route for the removal of tar from the product gas of biomass gasification - A critical review. Chemical Engineering Journal 2020;382. https://doi.org/10.1016/j.cej.2019.122761

[33] Higman C. Gasification. 2nd edition. Amsterdam: Gulf Professional Pub./Elsevier Science; 2008. 